Chapman University

Chapman University Digital Commons

Education Faculty Articles and Research

College of Educational Studies

1992

\title{
Writing from the Margins: Geographies of Identity, Pedagogy, and Power
}

Henry A. Giroux

Pennsylvania State University

Peter McLaren

Chapman University, mclaren@chapman.edu

Follow this and additional works at: http://digitalcommons.chapman.edu/education_articles

Part of the Curriculum and Social Inquiry Commons, Linguistics Commons, and the Other Political Science Commons

\section{Recommended Citation}

Giroux, H. A. , \& McLaren, P. (1992). Writing from the margins: Geographies of identity, pedagogy, and power. Journal of Education, 174(1): 7-30.

This Article is brought to you for free and open access by the College of Educational Studies at Chapman University Digital Commons. It has been accepted for inclusion in Education Faculty Articles and Research by an authorized administrator of Chapman University Digital Commons. For more

information, please contact laughtin@chapman.edu. 


\section{Writing from the Margins: Geographies of Identity, Pedagogy, and Power}

\section{Comments}

This article was originally published in Journal of Education, volume 174, issue 1, in 1992.

\section{Creative Commons License}

(c)

This work is licensed under a Creative Commons Attribution 3.0 License.

\section{Copyright}

Trustees of Boston 


\title{
WRITING FROM THE MARGINS: GEOGRAPHIES OF IDENTITY, PEDAGOGY, AND POWER
}

\author{
Henry A. Giroux \\ Pennsylvania State University, University Park, Pennsylvania
}

\section{Peter McLaren}

Miami University, Oxford, Ohio

The excess of language alerts us to the ways in which discourse is inextricably tied not just to the proliferation of meanings, but also to the production of individual and social identities over time within conditions of inequality. As a political issue, language operates as a site of struggle among different groups who for various reasons police its borders, meanings, and orderings. Pedagogically, language provides the self-definitions upon which people act, negotiate various subject positions, and undertake a process of naming and renaming the relations between themselves, others, and the world.

Educational theory is the discursive face of literacy, pedagogy, and cultural politics. It is within theory and its concern with the prohibitions, exclusions, and policing of language along with its classification, ordering, and dissemination of discourse that knowledge materializes, identities are formed and unformed, collective agents arise, and critical practice is offered the conditions in which to emerge.

At the current moment, language is being mobilized within a populist authoritarian ideology that ties it to a tidy relation among national identity, culture, and literacy. As the cultural mask of hegemony, language is being mobilized to police the borders of an ideologically discursive divide that separates dominant from subordinate groups, whites from Blacks, and schools from the imperatives of democratic public life.

Current attempts at providing a language for examining the process of schooling, for conducting research in educational settings, and for gaining greater access to a more critical understanding of the social, cultural, and political dimensions of learning have been less than satisfactory. In fact, they have been gravely inadequate. Educational research needs a new theory that

This is a revised version of Henry A. Giroux and Peter McLaren, "Language, Schooling and Subjectivity: Beyond a Pedagogy of Reproduction and Resistance," in Kathryn M. Borman, Piyush Swami, and Lonnie P. Wagstaff, eds., Contemporary Issues in U.S. Education (Norwood, New Jersey: Ablex).

Journal of Education, Volume 174, Number 1, 1992.

(c) Trustees of Boston University 
takes seriously how language and subjectivity intersect with history, power, and authority. The absence of such a theory is evident not only within the domain of mainstream research on schooling but also in the failings of critical theorists. As a group, we have failed to develop a comprehensive understanding of language, identity, and experience and their relation to the broader power-sensitive discourses of power, democracy, social justice, and historical memory. It is true that feminist, poststructuralist, and postmodern theories have greatly expanded how we understand the relationship between identity, language, and schooling; but all too often these discourses collapse into a dehistoricizing and self-congratulatory emphasis on articulating the specifics of ethnographic methodologies and the ideological virtues of asserting the importance of naming one's location as a complex discursive site. As essential as these theoretical forays have been, they often abuse their own insights by focusing on identity at the expense of power. Language in these texts becomes a discursive marker for registering and affirming difference but in doing so fails to address how they are related within broader networks of domination and exploitation. In part, this may be due to the ahistorical quality of this work. Lacking a historical context, they fail to engage the political projects that characterized older versions of critical pedagogy and end up failing to locate their own politics and its value for larger social, political, and pedagogical struggles.

In effect by downplaying the importance of the historically constructed relationship between language and power, critical educators have failed to develop a discourse that articulates issues of identity, place, pedagogy, and history with a language of vision and public life. (This is developed in Giroux, Border Crossings, 1992.)

The first section of the paper outlines the current crisis in critical pedagogy which we describe as an inability to move beyond a language of critique and domination. In the second section we examine the relation of language to the formation of subjectivity and praxis and try to persuade the reader that the choice of language we make as educators in describing, interpreting, and analyzing social reality is a crucial factor in educational and social change. In the third section we move from a discussion of how language works to socially construct and mediate reality, and how language interacts with experience to shape subjectivity, to the current debate among critical educators regarding whether or not the language of radical educational theory is too abstruse and impractical. Lastly, we outline provisional elements of a critical pedagogy for classroom use that offers the potential for helping to create an active, critical citizenry of learners in the current age of postmodern media knowledges. 


\section{Critical Pedagogy and the Crisis within the Language of Theory}

Radical pedagogy as it has been developing in both England and the United States for the last decade has drawn heavily upon particular forms of political economy, ideology critique, and cultural criticism. Its main task - and important achievement - is that it has challenged what can be loosely termed the ideology of traditional educational theory and practice. Traditional educational research attempted the paradoxical feat of depoliticizing the language of schooling while reproducing and legitimating the cultural and political authority of dominant groups. In opposition to the traditionalists' attempt to theoretically suppress important questions regarding the relations which obtain among knowledge, power, and domination, critical educational theorists were able to develop new theoretical languages and modes of criticism to suggest that schools were largely /though not exclusively) agencies of social, economic, and cultural production. At best, public schooling offered limited mobility to members of subordinate classes but, in the final analysis, served primarily as a powerful instrument for the reproduction of capitalist social relations and the dominant legitimating ideologies of ruling groups.

In spite of its success at developing insightful theoretical and political analyses of schooling, radical educational theory suffered from some serious flaws, the most significant being its failure to move beyond the language of critique and domination. That is, radical educators remained mired in a language that linked schools primarily to the ideologies and practices of domination. In this view, schools were seen almost exclusively as agencies of social reproduction, producing obedient workers for industrial capital. Radicals generally dismissed school knowledge as a form of bourgeois ideology, and often portrayed teachers as being trapped in an apparatus of domination that worked with a relentless precision and lockstep certainty.

Of course, the reproductive model of schooling became more and more sophisticated theoretically over time. Critical theorists used it to explore the role schools have played in capital accumulation, ideological legitimation, and production of knowledge necessary to carry on the increasing demands of a changing capitalist society. But, while the theory was extended to a set of wider concerns such as gender relations and the political economy of publishing, its underlying logic did not change. It still provides a model in which everything operated within and in response to the logic of capital. Put bluntly, the reproductive theory of schooling is a reactive mode of analysis, one that repeatedly oversimplifies the complexity of social and cultural life. It ultimately ignores the need to create a theoretical discourse that transcends the imperatives of possibility within existing capitalist configurations of power. The major failure of this position has been that it prevents left educators from developing a programmatic language in which they can 
theorize for schools. Instead, these radical educators have theorized primarily about schools. Writing off schools as agencies of domination, they have seldom concerned themselves with trying to construct new, alternative approaches to school organization, curricula, and classroom social relations.

Radical educational theory has been burdened by more than the language of critique. It has also failed to explore and develop a number of important concerns that are central to a critical theory of schooling. First, as a group we have failed to develop a public philosophy that integrates the issues of power, politics, and possibility with respect to the role that schools might play as democratic public spheres. Most radical educational theorists have been so caught up in describing the reality of existing schools that they have failed to take up the question of what it is that schools should be. Lacking any substantive vision, most radical theorists have ignored the task of developing the foundation of a progressive public philosophy as a referent for reconstructing schools as democratic public spheres. In this case, such educators have failed to construct a programmatic discourse for providing students with the knowledge, skills, and values they will need, not only to find their own voices, but to understand these voices and to use them to constitute themselves as collective social agents.

Second, radical educational theorists as a group have eschewed trying to develop a theory of ethics that can either justify our own language or legitimate the social practices necessary for defending a particular vision of what schools might become. Caught within the paradox of exhibiting moral indignation without the benefit of a well-defined theory of ethics and morality, we have been unable to move from a posture of criticism to one of substantive vision. We are caught on a shifting ground regarding ethical principles that inform such a discourse. We have rarely discussed what the moral referents might be for defending particular social and cultural practices, nor do we have a clear sense of what values need to be defended in the interest of an emancipatory vision of schooling.

Third, radical educational theory has been unable to analyze schools as sites which actively produce and legitimate privileged forms of subjectivity and ways of life. We have failed to analyze how subjectivities are schooled, how power organizes space, time, and the body, how language is used to both legitimate and marginalize different subject-positions, or how knowledge not only mystifies, but also functions to produce identities, desires, and needs. In effect, as Philip Corrigan (1987) has pointed out, there is no moral and political discourse in radical education theory that interrogates how existing social forms encourage, disrupt, cripple, dilute, marginalize, make possible, or sustain differentiated human capacities that extend the possibilities that individuals have for living in a truly democratic and life-affirming society and world. 
Fourth, radical educational theory has vastly underplayed the importance of redefining the actual roles that teachers might play as engaged critics and intellectuals in both the classroom and as part of a wider movement for social change. Teachers have been worked on but not included as self-determining agents of political and pedagogical change. For example, we have rarely addressed the role that teachers might play in alliance with parents and others as part of a wider educational and socio-political movement. Such alliances between teachers and the parents of Black, Latino, and low-income white children have been widespread during the Reagan-Bush era. For example, in Chicago parents joined with teachers in creating the Parent Equalizers of Chicago, headed by Dorothy Tillman. As a result of this movement, hundreds of parents were educated about the workings of the school system, how to get actively involved in the schools, and how to get elected to various levels of policymaking boards. These parents got rid of the Mastery Learning Reading Program, created Local School Improvement Councils, and have played an active role in promoting school criticism and educational reform. This is exactly the type of movement that radical educational theorists need to take into account when we write about presentday schools and the role of teachers. We have to be alert for signs of potential change in the schools, in the direction of greater democracy.

\section{Language and Reality: Conceptual Underpinnings}

In order to address some of the problems we have underscored in the previous section, we want to focus on the need for a more comprehensive theoretical language that is capable of conceiving schools as complex sites which cannot be understood solely within the modalities of reproduction or resistance theory. Part of the project of transforming our understanding of schooling is how we talk about the process of schooling itself. This, in turn, involves a struggle over the theoretical and ethical vocabulary we employ in analyzing how schools work and function in our society. We want to argue that the purpose of developing a critical language of schooling is not to describe the world more objectively, but to create a more ethically empowering world which encourages a greater awareness of the way in which power can be mobilized for the purposes of human liberation. Critical educational theory needs a language that understands how experience is produced, legitimated, and organized as a central aspect of pedagogy. We need to examine language and its production as a form of historical argument; furthermore, we need a language that is critical about its own mechanisms of authority. The critical educational language which we envision is one in which difference is seen as a site of both affirmation and remaking, as a negotiated and complex critical practice in which the possibility of democratic public life becomes a central referent of both critique and possibility. 
To better understand schooling as a culturally complex, political enterprise is to recognize the social nature of language and its relationship to power and forms of knowledge. This relationship is critical for understanding the limitations of the way we currently interpret the role of schooling in our society. But before we explore this issue, it is important to know something about the way in which language functions as a mediator and as a constitutive factor of what we take to be reality. The first point we wish to emphasize is that language constitutes reality rather than merely reflecting it. Language in this case is not conceptualized as a transparent window to the world but rather as a symbolic medium that actively shapes and transforms the world. That is, language is the primary medium through which social identities are constructed, collective agents are formed, cultural hegemony secured, and emancipatory practice both named and acted upon (Fraser, 1992). Language is not some conduit to an immutable order of coherence and stability but is generative of the reality which it evokes and to which it speaks. Knowledge in this view is a social construction, which means that the world we inhabit as individuals is constructed symbolically by the mind (and body) through social interaction and is heavily dependent on culture, context, custom, and historical specificity (McLaren, 1988, 1989). What this means, according to Richard Brown, is that we must give up the bifurcation of the literal and objective from the metaphoric, symbolic, and subjective. Brown $(1987$, p. 118) has pointed out that "the realities to which symbols refer are also symbolic - that is...they are intended by human actors and within some shared frame of vision." For Brown, as for us, this suggests that words are not signs for things, but rather things are signs for words, since there is no social reality that is not experienced through a social matrix of discourse. While language is not the only source of reality (clearly there is a non-discursive world outside of language), it is largely through language that meaning is created.

This means that there is no ideal, monolithic, autonomous, pristine, or aboriginal world which can be understood outside the social nature of language and to which our social constructions necessarily correspond. There is always a referential field in which symbols are situated and this particular referential field (e.g., language, culture, place, time) will influence how symbols generate meaning. Language stamps the world with a social presence that is never neutral or unproblematic. Language does not reflect an untarnished image of reality "out there"; whatever image or object or event it attempts to render, it does so through refraction and distortion. This amounts to saying not that knowledge is always false but rather that it is never complete. We can say, therefore, that language produces particular understandings of the world: i.e., particular meanings.

When meaning is produced through language unreflectively to the extent that it gets sedimented into common-sense knowledge - which we 
call ideology - it tends to masquerade as "fixed truths" or "existing facts" about the social world, as if such facts were immune to particular relations of power or material interests. Language, however, is always situated within ideology and power/knowledge relations that govern and regulate the access of particular interpretive communities to specific language practices. And this is no less true of the language that we, as educators, employ in order to both understand theoretically our own work with students and to teach them. Meanings of any event or experience are only available through the language selected by the particular interpretive community wishing to render such events intelligible. Language is always located in discourses or families of ideas and the range of discourses is always limited or "selective" since the dominant culture has legitimated and made available certain discourses while discrediting and marginalizing others. The space of meaning is always a colonized space in which necessity has already been inscribed by cultural codes and the broader field of political, economic, and social relations. Language can therefore be used to frame and legitimate different readings of the world. It is both a symptom and a cause of our cultural understandings.

\section{Language and Subjectivity}

An important point about language, emphasized by Richard Brown and others, is that the language we use always implies a partisan political "advocacy of realities"; it always acts as a form of "persuasive symbolization" - that is, it always acts rhetorically (Brown, 1987, pp. 97-117). The idea here which Brown is stressing is that truth is not independent of the political and linguistic processes and purposes by which it is evoked. In other words, truth cannot be named outside of its rhetorical dimensions. In this sense we can agree with Robert Scholes that language in some sense always contains an aspect of violence and alienation in that as part of the process of naming reality it separates human beings from that, the thing, that is named (Scholes, 1985, pp. 111-112). Moreover, every time we use language, we engage in a highly partisan socio-political act. Using language is partisan and political because each time we use it, we embody how cultural processes have been written on us and how we in turn write and produce our own scripts for naming and negotiating reality. We both produce language and are produced in it. We can claim no diplomatic immunity from the consequences of the language we employ. Identity largely resides within the rhetorical dimensions of language, that is, within the political and linguistic processes by which it is summoned into being (Brown, 1987, p. 81). The language we use to read the world determines to a large extent the way we think and act in and on the world (Volosinov, 1973).

If it is true that we make sense of social reality through language which is always replete with a range of discourses supported by material interests and forms of social power, then it follows that through language we are 
produced as subjects (i.e., provided with available subject positions or points of view). Following this, it can also be said that language helps constitute subjectivity, which is often constructed out of a multiplicity of subject positions (see the excellent discussion of subjectivity in Weedon, 1987). We use the term "subjectivity" here as distinct from identity because subjectivity permits us to acknowledge and address the ways in which individuals make sense of their experiences, including their conscious and unconscious understandings, and the cultural forms available through which such understandings are either constrained or enabled. The term "identity" on the other hand implies that there is a fixed essence that exists independently of the range of discourses made available to individuals. That is, the term identity suggests a unitary, self-constituting sovereign subject whose autonomous, primordial characteristics are pre-discursive in nature, allegedly constituted outside of language, history, or power. Karl Racevskis underscores this point when he writes:

\begin{abstract}
Identity is what is naturally given and is therefore considered a possession, yet it is also that which possesses the individual. If, on the one hand, identity is constituted by a personal experience and an individual history, it is also inevitably a product of the otherness of cultural, social, and linguistic determinants. As the individual reconstructs and reflects upon an imaginary identity, he/she cultivates an illusion of conscious control that only serves to occlude the aleatory and contingent nature of this imaginary essence. $(1988, \mathrm{p} .21)$
\end{abstract}

In this context, identity is imaginary (in the Lacanian sense) and, according to feminist theorists such as Luce Irigaray, such a construction of the self is unvariably and unavoidably male (see Whitford, 1988). Jane Flax (1990) points out that even in postmodernist theories certain patriarchal dispositions are produced. She is worth quoting:

In postmodern philosophies woman is often still utilized as the other or as mirror for Man; when she exists at all, it is as the repository for the qualities Man has denied to himself and now wishes to reclaim. Woman's speech is constricted by these rules - or she is (and may remain) silenced. As Irigaray so aptly puts it, woman is "for them - but always according to him - essentially an-archic and a-teleological. For the imperative that is imposed on them - but solely from the outside, and not without violence - is 'enjoy without law'. . . when that strange state of 'body' that men call woman's pleasure turns up, it is gratuitous, accidental, unforeseen, 'supplementary' to the essential." (Flax, 1990, p. 226)

Subjectivity, on the other hand, suggests an individual presence without essence. It underscores the contingency of identity and the fact that individuals consist of a decentered flux of subject positions, highly dependent 
upon discourse, social structure, repetition, memory, and affective investment to maintain a sense of coherence in a world of constant change. We prefer this term because it stresses the fact that a subject position is a standpoint taken up by a speaker within a discourse which may be affirmed or opposed to the positions taken up by other speakers. Discourses are invested in material and institutional forms and governed by discursive practices which, after Foucault, refer to the anonymous historical rules that govern what can be said and what must remain unsaid, who can speak with authority and who must listen (see McLaren, 1989). From the perspective of schooling, a discourse can be defined as a "regulated system of statements" that establish differences between fields and theories of education (Smith \& Zantiotis, 1989). Since discourses emerge from and are constitutive of particular configurations of power, they are necessarily tied to an ideological position. Discourses are ideological not simply as reflections of an economic base, but in their effects of power. As such, they may be considered in themselves material practices. Discourses locate history not in the register of a universalized notion of truth, but rather in that of signifying practices (Kaplan, 1987, p. 23). Such signifying practices are taken up with a politics of location or from the positionality of the individual which is informed by race, class, gender, sexual orientation, and other social and cultural determinations.

We usually consent to assuming subject positions which are familiar to us and in which we feel comfortable. It is through the textual grammar of discourse (i.e., the rules by which meanings are generated) that we constitute ourselves as a polity and we also note, along with Richard Brown, that "transformation of the grammars of a polity is a definition of revolution" (Brown, 1987, p. 128). We argue that discourses do not totally cement identities or subjectivities but produce a range of subject positions around which subjectivities tend to cluster and/or resist each other (Donald, 1985, p. 344).

\section{Language, Experience, and Praxis}

The importance of language resides in the fact that it is through language that we both name experience and act as a result of how we interpret that experience. This is important not only for researchers attempting to understand the process of schooling but also for students who are attempting to critically analyze their everyday experience. The struggle over how to name and transform experience is one of the most crucial issues in critical pedagogy and the fight for social change. This struggle is, in part, influenced by the struggle over language and how it is employed. As a socially organized and culturally produced human practice, language never acts on its own but only in conjunction with readers, their social locations, their histories, and 
their subjective needs and desires. Only when we can name our experiences - give voice to our own world and affirm ourselves as active social agents with a will and purpose - can we begin to transform the meaning of those experiences by critically examining the assumptions upon which those experiences are built. Using language in specific ways can help to constrain or enable particular forms of behavior. This can be seen in the language used by critical ethnographers and action researchers who, having theorized the dominant culture as imposing oppressive constraints on their subjects under study, have often worked to change the oppressive features operating within their research sites rather than simply describing them. Without a theory of domination, researchers often consider their sites as value neutral and choose to act as disinterested, "objective" observers.

Educational researchers who are able to name social injustice often extend their role of researchers to that of social activists. But if the concepts of domination and oppression are not part of a researcher's vocabulary, then it often follows that the researcher's analysis will likely remain disinterested, neutral, and devoid of social criticism. Language traffics in power through its ability to accommodate, produce, and resist historically specific configurations of power. As a dominating practice, language usage implicates itself not merely by naming the world so as to support relations of oppression and exploitation, but also through its unwillingness to interrogate the constructed nature of its own categories and the selective visions it embodies in its own social geography. The language of mainstream educational theory often becomes in this instance an oppressive totalizing system precisely because it is incapable of interrogating its own discursive production of the real and the social relations it both constructs and sustains, relations which often deny rather than enable a life without exploitation and human suffering.

Krystyna Pomorska writes that predicating or naming constitutes the nucleus of the creative power of language and that in "predicating or naming, we create the reality" (cited in Brown, 1987, p. 127). The nature of the language we use determines how we make sense of our experiences and the type of social action we choose to engage in as a result of interpreting our experiences. It also determines the range of possibilities we have to organize our social world, to develop new forms of sociality, and, as teachers, new forms of pedagogy. If experience is largely understood through language, and language shapes how we see and act with and on the world, then it follows that experience itself does not guarantee truth since it is always open to conflicting and contradictory interpretations. That is, our experience is not some fixed or fluid essence, or some concrete reality that exists prior to language, waiting to be reflected by language. Rather, experience is constituted by language (Weedon, 1987, p. 85).

Experience - "events and behaviors occurring in social formations" (De Lauretis, 1987, p. 42) - is highly constitutive of subjectivity. Since 
language enables us to interpret our experience then it follows that language is also constitutive of subjectivity. We have noted that experience does not speak for itself, outside the frames of reference (discourses) associated with the language we select or are given in order to make sense of that experience. The serious issue here deals with the ways in which we have been inserted into language both as teachers and students. To reflectively situate ourselves in discourse - in language - is to historicize our role as social agents. If we think only those thoughts which we already have the words to express, then our presence in history remains static. Part of the state of this crisis is reflected in the unavailability of subject positions in which students are permitted to practice forms of radical critique and engage in social practices informed by a commitment to establishing a more democratic social order.

Teachers and students are given subject positions in language which govern their range of perspectives in interpreting the world. Access to particular forms of subjectivity is also regulated by the act of reading itself, in addition to institutionalized social relations and power relations which often provide the context for privileging certain readings on the basis of race, class, and gender. Take the example of gender-constructed subjectivities; as Chris Weedon points out, dominant discourses of female sexuality define sexuality among women as naturally passive and construct definitions of femininity which privilege a woman's subordinate role in the social order (Weedon, 1987, p. 36). Women's interests are subordinated to the interests of men through the exercise of patriarchical discourses. On this note, Leslie W. Rabine remarks that "the very structures of Western language exclude women and can function only through the silencing of women and the repression of feminine sexual desires" and that our future existence depends upon "overcoming androcentric structures of subjectivity" (Rabine, 1987-1988, p. 21). If subjectivity is structured by language, then the struggle becomes developing new forms of subjectivity and language which can integrate themselves into social struggles (p. 21). This oppression through language is no less true of the authorial discourses found in school classrooms than those found in medical consulting rooms, courts of law, or theories of schooling. Our subjectivities are constructed in language through the play of discourses and the subject positions which we consent to assume. Discourses cannot be understood outside the institutional patterns, forms of transmission, social practices, and material interests which inform and sustain them. Language, in itself, is not naturally gender-specific but the subject positions we assume within certain discourses are indeed gendered and are supported by patriarchal social and institutional power (Weedon, 1987, p. 173).

Texts create particular meanings and modes of understanding that need to be investigated. In our classrooms, we are beginning to recognize the paucity of texts of women's historical resistance to patriarchy (which amounts to the very silencing of women) which has deprived students of the 
history of alternative resistant subject positions which illustrate the nonnatural status of current gender norms (Weedon, 1987, p. 170). Weedon's warning is important: "While we need texts that affirm marginalized subject positions, however, it is important to be constantly wary of the dangers of fixing subject positions and meanings beyond the moment when they are politically productive" (p. 172).

What Weedon is stressing is that all texts (and we are using the term "text" to mean various representations such as institutions, classrooms, behaviors, and social practices) need to be understood in their historical, political, and cultural specificity. That is, no texts are meant the same way by readers who occupy different contexts, at different historical junctures. For instance, it is wrong to assume that the readings engaged in by women and men, or the affluent and the poor, are homogeneous. Addressing this point, Tony Bennett acknowledges the reiterative and already coded status of knowledge production. Bennett cuts across the notion of the unique, unitary experience of reading meaning by arguing that subjects approach a text with already coded perceptions of what he calls "reading formations," comprising a set of discursive and textual determinations which organize and animate the practice of reading (Bennett, 1986; see also summary in Kaplan, 1987, pp. 26-27). These reading formations may, as Bennett notes, be shaped by the dominant codes that govern the popular text or by subcultural codes such as feminism, trade unionism, Marxism, Moral Majority thinking, white supremacist thinking, etc. In some cases, the reader refuses the offered position and denies interpolation and there may also be an ideological discrepancy in relation to race. The question for educators may be summarized as: To what extent do conventional schooling practices duplicate the already constructed reading formations of teachers and students?

So far in our discussion it appears that the die is cast, that the "language game" has fixed us as students, teachers, and researchers as subjects "always already spoken" by discourse rather than permitting us to become social agents actively contesting the prison house of language. In order to break free from the prison house of language as students, teachers, and researchers, we need to understand that reality is not co-extensive with the categories of discourse, since failing to do so means limiting social change to the permutations of discourse within the same set of categories (Whitford, 1988, p. 120). Allan Megill reminds us that "if one adopts. . . the view that everything is discourse or text or fiction, the realia are trivialized. Real people who really died in the gas chambers at Auschwitz or Treblinka become so much discourse" (1985, p. 345).

Luce Irigaray and Cornelius Castoriadis urge us to struggle for change within the social unconscious or symbolic order itself; we need to believe that "radical transformations in the social imaginary can take place, and [a] new and previously unimaginable configuration [can] take shape" (Whitford, 
1988, p. 121). It is in the arena of the social imaginary that critical pedagogy as a form of cultural politics can make a necessary intervention. In recognizing that individuals are produced through the clash of conflicting discourses and subject positions, critical pedagogy can help us to critically interrogate those discourses, allowing us to develop a sense of "critical agency." Agency, in this case, refers to the ability of individuals to analyze subjectivity, reflect upon subject positions they have assumed, and choose those which are the least oppressive to themselves, to others, and to society as a whole.

What this means pedagogically for critical educators is not easy to articulate. For students this means teaching them to read texts as languages constructed through the ordering of particular codes which name and legitimate reality and social identities in specific ways. Students need to learn how to read not as a process of submission to the authority of the text but as a dialectical process of understanding, criticizing, and transforming. They need to write and rewrite the stories in the texts they read so as to be able to more readily identify and challenge, if necessary, how such texts actively work to construct their own histories and voices. Reading a text must be a way of learning how to choose, how to construct a voice, and how to locate oneself in history. This amounts to intervening differently in one's own self formation and the self formation of others. Since discourses which work through language lead to particular social and institutional practices, a knowledge of the discourses that inform our subjectivities can lead to the construction of new forms of subjectivities, social relations, and institutional arrangements more hospitable to equality and social justice. For teachers and educational researchers this means being able to recognize the limitations which mainstream social theory has placed on the way we understand schooling and its relationship to the wider society and how this has shaped our subjectivities as intellectuals engaged in naming and producing a particular view of the world.

We all speak from complex subject positions, which amounts to saying that we can never escape ideology or the effects of discourse. Subject positions, as we have noted, grant us the illusion of being temporarily fixed as autonomous authors of meaning and agents of social practice. The point is not to lament our lack of total autonomy but to actively engage in forms of "critical agency" by learning how to negotiate, translate, resist, and transform power arrangements and interests which are legitimated by uncritically assuming particular subject positions. What we are guarding against here is the overdetermination of language in the production of the social subject. As Richard Johnson notes, we must take seriously the notion of political will and the discursive self-production of subjects (Johnson, 1986/87, p. 69).

The issue, of course, is how through the language of educational analysis teachers have become produced as social subjects and how this affects 
their roles as researchers and instructors. Once educators recognize the manifold ways in which they are produced through language, they can start to provide for their students a critical language that will help them to become conscious of their own self-formation. In the next section we wish to describe more specifically some prevailing problems with the language that presently constitutes radical educational theory.

\section{Language and the Primacy of the Political Project}

Language is always constructed with respect to the specificity of the audience it addresses and should be judged not only in pragmatic terms but also with respect to the theoretical and political viability of the project it articulates. It is not primarily the complexity of language which is at issue but the viability of the theoretical framework it constitutes and promotes. Moreover, the relationship between theory and practice is multifaceted and complex. Simply put, theory in some instances directly informs practice, while in others, practice restructures theory as a primary force for change. In some cases theory (in the more limited sense of the practice of producing narrative and rhetoric) provides the refuge to think beyond current forms of practice so as to envision that which is "not yet." Privileging practice without due consideration of the complex interactions that mark the totality of theory/practice and language/meaning relationships is not simply reductionistic but also a form of theoretical tyranny. Disconfirming theory in this way becomes a form of practice that ignores the political value of "theoretical discourse" within a specific historical conjuncture. That is, rather than examining the language of theory as part of a wider historical moment of self-examination, the language and politics of theory is merely reduced to an unproblematic concern with clarity rather than the problematizing of certainty itself. The intimacy of the dialectic between theory and practice is reduced to an opposition between theory and complexity, on the one hand, and practice and clarity on the other. This is the mark of a vapid, pragmatic, anti-intellectualism whose leveling tendency occludes the role of language in constructing theory as a historically specific practice that makes politics and praxis possible as part of an engagement with the particularities and problems of a given time and place.

Within the present historical conjuncture, with its appeal to universality, its totalitarian view of history, its ethnocentric embrace of culture, and its celebration of greed and individualism, the questions to be asked about language and theory might begin with the conditions necessary to develop forms of theoretical practice capable of retrieving history as the discourse of the Other, reclaiming democracy as a site of struggle within a wider socialist vision, and developing a radical ethic that rejects finality and consensus for the voice of difference and dialogue. At the present time, theory 
offers the opportunity for a discursive practice whose identity and political value can only be understood in particular circumstances, informed by the historical conjuncture that gives it meaning. As Bruce Robbins puts it, the real debate over theory is about both the specific ideological content of various theoretical discourses and the "circumstances that give these ideas their limits and their cogency" (Robbins, 1987/88, p. 9). At issue here is whether the language of theory works in the interest of making the familiar strange, acknowledging difference as the basis for a public philosophy that rejects totalizing theories which view the other as a deficit, and providing questions the dominant culture finds too dangerous to raise. What many "radical" educators forget is that the importance of language as a theoretical practice derives from its power as a critical and subversive discourse. To judge theory next to the simple yardstick of clarity more often than not represents a specific theoretical discourse incapable of reflecting on its own practice within the present historical conjuncture, a practice that has more to do with a defense of the status quo than it does with a viable politics of theory, language, and schooling.

In addition to arguing against the concern for clarity over that of the political project that language seeks to illuminate and further, we also are wary of the new poststructuralist discourses which often fetishize the text at the expense of those whom its analysis is supposed to serve. We would like to make clear at the outset that the type of critical language that we are advocating does not endorse, as do deconstructionists such as Derrida, the position of anti-referentiality (the denial of the possibility of presence, perception, and also experience, which is implied in the claim that we never experience anything because we encounter only deferred traces of things, that is, only a structure of infinite referral or pure differences in which there are only traces prior to any entity to which they refer). Similarly, we do not wish to erase the world by arguing that reference is simply a mirage of language. This is not the same as arguing for unmediated perception or to claim that the world is not textualized by relations of power and interest; rather, it is, in the words of Robert Scholes, to assert that language accommodates reality as much as constructs it, that "human language intervenes in a world that has already intervened in language" (Scholes, 1985, p. 112). We are in no way suggesting that poststructuralist and deconstructive social theory in its totality is to be rejected. Such a position is ludicrous and fails to understand many of the important theoretical gains made by various proponents arguing from these perspectives. We are especially impressed with the poststructuralist argument which asserts that there are no grand theories with which to justify social practices as neutral and apolitical - that is, outside of ideology and beyond historical specificity and struggle. Moreover we fully endorse those deconstructive and poststructuralist approaches which suggest that the Enlightenment conceptions of knowledge, truth, objectivity, and reason are the effects of asymmetrical forms of social power. 
Our main concern with the poststructuralist legacy and its various eruptions in literary criticism, drama theory, and elsewhere in the academy is the way in which it denies the viability of political work by enacting the discourse of profound skepticism. Its overall lack of a public philosophy, its lack of organic connections to a wider public sphere, its suffocating emphasis on a narrow notion of textuality, its domination by intellectuals from elite schools, and its almost unreadable pedanticism make it less a threat to the established configurations of power than an unwilling ally. There is a domesticating element in its practice, an elitism that threatens to suffocate its most important theoretical insights by cutting it off from those who are really oppressed, and a smugness that substitutes academic convention for real substance and action. There is a certain politeness that governs this discourse that makes it too tame to take seriously, a narrowness of vision that feeds the very society it claims to oppose. Robert Scholes speaks to some of these issues:

For the generation whose sensibilities were shaped by the sixties, the anarchistic irreverence of deconstruction holds a profound attraction. For those who still remember the slogans of the past well enough to think of themselves as having sold out, as having been co-opted by the establishment, the verbal or textual posture offered by deconstructive discourse is almost irresistible. Its appeal is so strong because it allows a displacement of political activism into a textual world where anarchy can become the establishment without threatening the actual seats of political and economic power. Political radicalism may thus be drained off or sublimated into a textual radicalism that can happily theorize its own disconnection from unpleasant realities. (Scholes, 1988, p. 284)

Within the context of higher education in the United States, deconstruction has narrowed the range and substance of resistance by displacing older categories of oppression such as class, gender, and race (Giroux \& Simon, 1988); similarly, it has undermined the notion of agency at a time when many subordinate groups are trying to locate themselves as part of a wider social movement for cultural, economic, and political justice. It is with this sentiment in mind that Barbara Christian writes:

The new emphasis on literary critical theory is as hegemonic as the world which it attacks. I see the language it creates as one which mystifies rather than clarifies our condition, making it possible for a few people who know that particular language to control the critical scene - that language surfaced, interestingly enough, just when the literature of peoples of color, of black women, of Latin Americans, of Africans began to move to "the center." (1987, p. 55) 


\section{Developing a Discourse of Critical Pedagogy and Critical Literacy}

In this final section we attempt to offer an outline of an approach to teaching which takes seriously the question of knowledge production through language and experience. Critical pedagogy takes as one of its most fundamental aims an understanding of how the socially constructed and often contradictory experiences and needs of students might be made problematic so as to provide the basis for exploring the interface between their own lives and the constraints and possibilities within the wider social order. Traditionally, radical educators have emphasized the ideological nature of knowledge (either as a form of ideology-critique or as ideologically correct content to get across to students) as the primary focus for critical educational work. Central to this perspective is a view of knowledge that suggests that it is produced in the head of the educator or teacher/theorist and not in an interactional and primarily cultural engagement expressed through the process of writing, talking, debating, and struggling over what counts as legitimate knowledge. Within this perspective, the production of knowledge is limited to what goes on outside of the classroom, and the ways in which teachers, students, and texts interact to produce particular readings and forms of knowledge are generally ignored. A critical theory of schooling needs to acknowledge that the pedagogical process itself represents an important aspect of the production of knowledge in classrooms. This is crucial not only in order to understand how students actively draw upon their own cultural resources in order to produce meaning, but also because it theoretically legitimates the various forms of investments that students make in the learning process itself. Pedagogy itself is not merely concerned with transmitting knowledge; it is primarily concerned with how knowledge is productive of both meaning and affect, how it comes into being as a cultural currency that resonates and extends the interests that both teachers and students legitimate within the context of the classroom.

The type of critical pedagogy of language and experience that derives from the productive and interactive processes that make up the classroom encounter is fundamentally concerned with student experience in a threefold sense. First, the concept of student experience is validated as a primary source of knowledge and student subjectivity is seen as a multilayered, often contradictory repository of meanings. In this perspective, experience and subjectivity do not collapse into the humanist notion of the integrated ego as the source of all actions and behavior (although this position has tended to avoid looking at how memory and history work to provide some sense of fluid continuity to the self). Similarly, if student experience is viewed as constituted out of difference and rooted in contradictory discursive and nondiscursive practices, then both the experiences that students bring to 
schools and the cultural forms out of which they are produced operate within tensions that are never closed or unassailable. The concept of the subject that emerges from our view of student experience as a terrain of struggle is articulated by Larry Grossberg:

This "post-humanistic" subject does not exist with a unified identity (even understood as an articulated hierarchical structure of its various subjectpositionings) that somehow manifests itself in every practice. Rather, it is a subject that is constantly remade, reshaped as a mobilely situated set of relations in a fluid context. The nomadic subject is amoeba-like, struggling to win some space for itself in its local situation. The subject itself has become a site of struggle, an ongoing site of articulation with its own history, determinations and effects. (1985, p. 72)

Second, such a pedagogy attempts to provide students with the critical means to negotiate and translate critically their own particular lived experiences and subordinate knowledge forms. This means assisting students in analyzing their own cultural meanings and interpretations of events so as to illuminate and intervene into the processes by which they are produced, legitimated, or disconfirmed. Student experience is the fundamental medium of culture, agency, and identity formation and must be given preeminence in emancipatory curriculum. It is therefore imperative that critical educators learn how to understand, affirm, and analyze such experience. This means not only recognizing the limits and possibilities which inhere in the cultural and social forms through which students learn how to define themselves, but also learning how to engage student experience within a pedagogy that is both affirmative and critical and which offers the means for self and social transformation. (These issues are more fully developed in Giroux, 1988.)

Third, a radical discourse of pedagogy needs to incorporate a viable theory of critical literacy, one which in this case focuses on the interests and assumptions that inform the generation of knowledge itself. This is particularly important for developing a pedagogy, as Paulo Freire would put it, for both reading the world and reading the word (see Freire \& Macedo, 1988).

School texts are, for the most part, the products of the interests that inform dominant social and cultural groups. Critical literacy attempts to destabilize the constellations of reified facts and to defamiliarize the domesticating myths which often serve to legitimate existing relations of power and privilege among dominant groups. Texts are interrogated for what they do not say - for their "structured silences" - as well as for what they do say. To operate from a position of critical literacy is to recognize that knowledge never speaks for itself (see Giroux, 1987). Even the alleged great works of literature do not transcend history or the contextual specificity of the discourses which generated them; to argue that these works deserve to be 
universally conserved regardless of the particular characteristics of the students whom the curriculum is intended to serve is to fail to make this recognition. That is, knowledge must not be presented as inexorably given and self-justified by its academic valoration through the ages but must be approached as a form of production with a view to the socially constitutive nature of both readers and texts. In this way educators can come to understand why, for instance, the high-status knowledge of classic literary works has become the only kind of knowledge deemed immutable and sacred enough to warrant its inclusion in the proposed "national" curriculum and why the subjugated knowledges of economically disadvantaged groups, women, and minorities are insistently denigrated.

A pedagogy of critical literacy must do more than interrogate and demystify the interests that inform dominant knowledge forms; it must also include and bring to the center of the curriculum those forms of knowledge that constitute the spheres of the everyday and the popular. These are forms of knowledge which constitute student experience; they are also part of those wider cultural formations that promote forms of manipulation unmatched historically in this country. Mass and popular knowledge is deconstructed as part of a critical theory of teaching and learning. Educators need to acquire more knowledge about how students invest themselves in such mass and popular knowledge forms; they need to understand how such knowledge forms operate through various circuits of power: their production in the economy, their legitimation in the mass market, and their appropriation by students. For critical literacy to be effective, it must be embedded in the concrete lived conditions of the students themselves. In this regard, it is especially important to explore the connection between student alienation and classroom resistance to new narrative forms currently being constructed in the domain of the popular. A critical literacy situates itself in the intersection of language, culture, power, and history - the nexus in which the subjectivities of students are formed through incorporation, accommodation, and contestation. The struggle is one that involves their history, their language, and their culture. What makes literacy "critical" is its ability to make the learner aware of how relations of power, institutional structures, and models of representation work on and through the learner's mind and body to keep him or her powerless, imprisoned in a culture of silence. In fact, a critical perspective demands that the very ideological process of language itself be interrogated. 
A pedagogy of language and of experience means teaching students to read both the word, image, and the world critically, with an awareness of the cultural coding and ideological production involved in various dimension of social life. This means, as Robert Scholes points out, teaching students to read, to interpret, and to criticize. In reading we produce a text within a text; in interpreting we create a text upon a text; and in criticizing we construct a text against a text. To read the world and the word means understanding the cultural and generic codes that enable us to construct words into a story - stories we can tell in our own words, and from different points of view. To interpret means being able to thematize and generalize about the narratives that constitute social experience: in short, it means to be able to tease out the hidden assumptions and motives that structure our everyday cultural system of values. In other words, it refers to grasping the ideological elements of our social world. To criticize means to understand the construction of social life as a particular mode of production which can be analyzed alongside other cultural texts which speak to other modes of ethical discourse and forms of sociality from which students can be called to ground their social action in the world.

In sum, what a critical pedagogy of language and experience attempts to do is to provide students with "counter-discourses" or "resistant subject positions" - in short, with a new language of analysis - through which they can assume a critical distance from their more familiar subject positions in order to engage in a cultural praxis better designed to further the project of social transformation. We need to assist students to inquire into the historical specificity of the production of their own subject positions and modes of sociality and their place in today's hegemonic network of social power. Power, as we have seen, is exercised through forms of subjectivity, which means that the subject positions which we assume uncritically and without a knowledge of more progressive alternatives can lead to the production of oppressive social practices. Of course, developing a critical pedagogy of language and experience for use with students can only follow from the development and employment of a new theoretical language for educators who wish to further their critical understanding of how schools work within the context of the larger society, and how they help to construct the subjectivities of the students who spend time within their walls for a significant portion of their young lives.

Clearly, critical pedagogy has performed an important service by illuminating through a language of critique conditions involving schools, the wider society, and the exercise of cultural power that might otherwise remain obscure or hidden. Its major ideological and political service has been to unravel the manner in which schools reproduce the logic of capital through the ideological and material forms of domination that structure the lives of 
students from various class, ethnic, and gendered groups. But in order to move beyond simply changing our opinion of schooling through a disclosure of schooling's oppressive conditions, it is necessary to embrace a different language of theoretical analysis which is capable of radically reshaping our very understanding of the school/society relationship. To achieve this, the hermeneutical net from which our current understandings of schooling are drawn must be restrung in order to capture a greater contextual understanding of the relation of schooling to economies of privilege and circuits of power at work in the larger society. A transformation of the oppressive dimensions of schooling must be preceded by a transformation of the language we use to speak about, and therefore comprehend, interpret, and criticize, the process and purpose of schooling.

\title{
Students as Cyborgs
}

While it is true that no language of theory has a privileged relation to reality, we want to emphasize the importance of pushing and reconfiguring the boundaries of the languages we use to understand the social life of the classroom and larger society in order to confront critically the new forms of literacies that are remaking both students and teachers within postmodern cultural contexts. Literacies are not just about language but also refer to the effects that cultural politics and social relations of power have upon the act of interpretation and the generation of meaning.

Jane Flax (1990, p. 222) writes that

\begin{abstract}
Like the use of languages, interpretation of meaning is not a purely private or unbounded process, but the rules may be so much a part of the game that it is hard to bring them to consciousness. Nor can the rules be understood solely within or generated by language because language and discursive rules both reflect and are located within complex contexts of social relations and power.
\end{abstract}

In attempting to provide an analysis of postmodern texts of identity, postmodern theorists (who are predominantly male) have failed to deconstruct their own acts of repression that, as part of a phallocentric textual economy, have marginalized or obscured women's acts of agency and mastery (Flax, 1990, p. 215). Critical pedagogy needs to develop modes of deconstructive analysis in which discourses of women do not depend on the congruences between what patriarchy assigns to women and the pervasive social meanings associated in our culture with being female.

One of the challenges we see in constructing a language and politics of representing social life and transforming our relations within it consists of examining new technologies, systems of significations, and reading practices that make few appeals to current standards of rationality. We are referring 
to the emergence of postmodern media knowledges (i.e., computers, television, film, interactive video, MTV, etc.) or information technologies that instantaneously transform our affective investments in discourses of desire and identity. These new information technologies have collapsed the boundaries between machines and human subjectivities, creating what Donna Haraway (1991) refers to as "cyborg" identities. Consider the fact that students are increasingly making what Bill Green and Chris Bigum (in press) call "cyborg couplings" outside of the classroom through inhabiting the cyberspace of Nintendo games, computer technology, VCRs, and MTV. This digital ecosystem produces contexts which are indeterminate and contingent instead of being anchored in biological or human time. Each school day students are ripped out of this techno-cocoon and placed in a 19th-century world of linear time and print technology. How can teachers provide a language of analysis to help these young cyborgs gain a critical understanding of their own techno-identities and how their desires have become constructed within the current proliferation of technocultures /Giroux \& McLaren, 1992)? Teachers require a critical language for students who are growing up in cyberspace, one that provides the opportunity for them to engage existing media literacies while "simultaneously making use of its technological advances" (McRobbie, 1992, p. 147). How can such a language be developed? How can we begin to map the more fluid boundaries of the postmodern self as constituted within new technologies and virtual realities that represent in themselves historically and culturally discrete systems of producing race, class, and gender relations? How can educators develop a language that does not textualize social reality such that they palliate the ground of historically concrete social relations from which real rebellion and resistance might occur?

In the symbolic realm there are many disparate sites and possibilities for struggle. Yet the world of concrete social relations and the unequal distribution of power and privilege that inform them are not simply texts to be analyzed but formations that must be resisted, ruptured, and transformed. In short, we need a critical pedagogy of language and experience in which the categories of understanding differences and otherness do not prohibit other differences from being named. We need a language that can help serve as an instrument for the student's discursive self-shaping and as a means for producing a collective political subject. This language is one that must be simultaneously engaged by students, deployed in strategic ways by teachers and cultural workers, and transformed in the interests of developing greater educational, political, economic, and cultural justice. 


\section{References}

Bennett, T. (1986). Texts in history: The determinations of readings and their texts. In D. Attridge, G. Bennington, \& R. Young (Eds.), Post-structuralism and the question of history (pp. 63-81). Cambridge: Cambridge University Press.

Bowles, S., \& Gintis, H. (1986). Democracy and capitalism. New York: Basic Books. Brown, R. H. (1987). Society as text: Essays on rhetoric, reason, and reality. Chicago: University of Chicago Press.

Christian, B. (1987, Spring). The race for theory. Cultural Critique, 6, 51-63.

Corrigan, P. (1987). In forming schooling. In D. W. Livingstone (Ed.), Critical pedagogy and cultural power. South Hadley, MA: Bergin \& Garvey.

De Lauretis, T. (1987). Technologies of gender. Bloomington: Indiana University Press.

Donald, J. (1985). Troublesome texts: On subjectivity and schooling. British Journal of Sociology of Education, 6(3), 341-351.

Flax, J. (1990). Thinking fragments: Psychoanalysis, feminism, and postmodernism in the contemporary West. Berkeley: University of California Press.

Fraser, N. (1992, Winter). The uses and abuses of French discourse theories for feminist politics. Theory, Culture, and Society, 9, 51-71.

Freire P., \& Macedo, D. (1988). Literacy: Reading the world and the word. South Hadley, MA: Bergin \& Garvey.

Giroux, H. A. (1987). Educational reform and the politics of teacher empowerment. New Education, 9(1/2), 3-13.

Giroux, H. A. (1988). Schooling and the struggle for public life. Minneapolis: University of Minnesota Press.

Giroux, H. A. (1992). Border crossings. New York: Routledge.

Giroux, H. A., \& Simon, R. I. (1988). Popular culture and critical pedagogy: Reconstructing the discourse of ideology and pleasure. Cultural Studies, 2(3), 294-320.

Giroux, H. A., \& McLaren, P. (1992). Media hegemony: Towards a critical pedagogy of representation. In J. Schwock, M. White, \& S. Reilly (Eds.), Media knowledge: Readings in popular culture, pedagogy, and critical citizenship (pp. xv-xxxiv). Albany, New York: State University of New York Press.

Green, W., \& Bigum, C. (in press). Aliens in the classroom. Australian Journal of Education.

Grossberg, L. (1986). History, politics and postmodernism: Stuart Hall and cultural studies. Journal of Communication Inquiry, 10(2), 61-77.

Haraway, D. J. (1991). Simians, cyborgs, and women. New York and London: Routledge. Johnson, R. (1986/87, Winter). What is cultural studies anyway? Social Text, pp. 33-80.

Kaplan, E. A. (1987). Rocking around the clock. New York and London: Methuen.

McLaren, P. (1988). Language, social structure and the production of subjectivity. Critical Pedagogy Networker, 1(2/3), 1-10.

McLaren, P. (1989). Life in schools. Albany, NY: Longman.

McRobbie, A. (1992, May). The Passagenwerk and the place of Walter Benjamin in cultural studies: Benjamin, cultural studies, and Marxist theories of art. Cultural Critique, 6(2), 147-169.

Megill, A. (1985). Prophets of extremity: Nietzsche, Heidegger, Foucault, Derrida. Berkeley: University of California Press.

Pomorska, K. (1980). The overcoded world of Solzhenitsyn. Poetics Today, 1(3), $163-170$.

Rabine, L. W. (1987-88, Winter). Ecriture Feminine as metaphor. Cultural Critique, No. 8 , pp. 19-44. 
Racevskis, K. (1988). Michel Foucault, Rameau's nephew, and the question of identity. In J. Bernauer \& D. Rasmussen (Eds.), The final Foucault (pp. 21-33). Cambridge: MA: MIT Press.

Robbins, B. (1987/88). The politics of theory. Social Text, 6(3), 3-18.

Scholes, R. (1985). Textual power. New Haven: Yale University Press.

Scholes, R. (1988, Winter). Deconstruction and communication. Critical Inquiry, 14, 278-295.

Smith, R., \& Zantiotis, A. (1989). Teacher education, cultural politics, and the avant-garde. In H. Giroux \& P. McLaren (Eds.), Schooling, politics, and cultural struggle. New York: SUNY Press, pp. 105-122.

Volosinov, V. N. (1973). Marxism and the philosophy of language. New York: Seminar Press.

Weedon, C. (1987). Feminist practice and poststructuralist theory. New York: Basil Blackwell.

Whitford, M. (1988). Luce Irigaray's critique of rationality. In M. Griffiths \& $M$. Whifford (Eds.), Feminist perspectives in philosophy (pp. 108-130). Bloomington: Indiana University Press. 